\title{
Развитие и распространение радикальных идей в условиях современных демократических обществ
}

\author{
Музылёв А. В., Харьковский национальный университет имени В. Н. Каразина
}

Установлено, что проблематика исследования радикализма будет актуальна и в дальнейшем. Успехи радикалов на выборах, мигрантский и экономический кризис, политическая нестабильность, массовые акции протеста - все это свидетельство того, что в крайних правых и крайних левых еще будет шанс выйти на политическую авансцену. Таким образом, демократия вовсе не является панацеей от развития радикальных идей. Она, как и другие формы правления, не защищена от всплеска популярности радикализма. Ключевой причиной, по которой именно в демократических обществах радикалы имеют наименьшую степень влияния, есть широкая возможность для выбора. Это позволяет человеку легче найти политическую силу или идеологию, которая в полной мере отражает его интересы.

Оценено влияние современных технологий и выявлено, что методы распространения радикальных доктрин приобретают все новые формы. Это порождает новые угрозы для демократии. Уже сейчас ежегодно растет количество протестов и погромов, не говоря уже об успехах радикальных политических сил на выборах, что можно считать ключевым показателем развития радикализма в условиях демократического общества. Главное, что могут сделать представители политического истеблишмента демократических государств, это попытаться снизить напряжение путем переговоров с представителями радикалов, ведь полностью искоренить крайне правых или левых не представляется возможным.

Таким образом, свобода собраний и коммуникаций, возможность добиться победы легитимным способом делает современные радикальные партии достаточно популярными. Используя традиционные приемы (жесткая риторика, упор на системные и коренные изменения, простота и доступность для каждого), они фактически предлагают ответы на вопросы, которые являются наиболее обсуждаемыми в обществе. Для демократии радикалы представляют определенную угрозу, поэтому от них часто пытаются отгородиться, но не во всех странах это проходит одинаково успешно. Например, националистические лозунги приносят дополнительные проценты голосов политическим партиям. Поскольку радикальные доктрины уже есть и по-прежнему создаются, то нет ничего удивительного в том, что они востребованны и никакие существующие виды запретов не способны на $100 \%$ решить данную проблематику.

Ключевые слова: политические режимы; экстремизм; делегитимация; терроризм; политические партии; тоталитаризм; прогосударственный экстремизм

\section{Development and dissemination of radical ideas in the conditions of modern democratic societies}

\author{
Muzylov O. V., V. N. Karazin Kharkiv National University
}

An analysis of theoretical sources demonstrates that the potential for the development of radicalism in a democracy is very high. Many prominent scientists have studied the problem, including P. Salmon, Ch. Mouffe, D. Della Porta. That freedom and scope for activities that appear in an individual in a democracy, allows you to freely seek political adherents or independently propagate the ideals of this or that doctrine. Democracy is not at all a panacea for the development of radical ideas. It, like other forms of government, is not immune from a surge in the popularity of radicalism.

In the conditions of totalitarian and authoritarian societies, the emergence and mass development of an ideology that would outshine the official one is extremely unlikely. As a result of the theoretical analysis was founded that modern communication tools play an important role, thanks to which people began to communicate much more with each other and exchange information. Social networks are not just places where like-minded people meet, but real spaces for recruiting radicals. This creates new threats to democracy. Already, the number of protests and pogroms is increasing every year, not to mention the success of radical political forces in the elections, which can be considered a key indicator of the development of radicalism in democratic societies.

Moreover, frustration in the current form of government can lead to massive confrontations of the civilian population with power structures. With this, the countries, in which the so-called «color revolutions» occurred repeatedly, came across. Representatives of political leaders of democratic countries usually recognize the right of people to vote and support radical parties, but they often oppose their successful results and refuse to cooperate with them, believing that such harm will damage their political reputation. For example, the incident occurred with the party «Swedish Democrats», when they did not want to be with them in the parliament. Such a reaction on the part of the democrats underscores once again that they are afraid of a real surge in the popularity of radical parties and movements, 
when it will be impossible to ignore them.

At the same time, many political forces already use radical slogans and slogans to achieve immediate goals. This is clearly seen in the example of the Ukrainian political parties, which used varying degrees of intensity of such speech in their own programs and in the speeches of their representatives. The study showed that it would not be possible to completely solve the problems of the popularity of radicalism, but it is quite possible to reduce the degree of social tension.

Keywords: political regimes; extremism; delegitimation; terrorism; political parties; totalitarianism; pro-state extremism

\title{
Розвиток і поширення радикальних ідей в умовах сучасних демократичних суспільств
}

\author{
Музильов О. В., Харківський національний університет імені В. Н. Каразіна
}

Встановлено, що проблематика дослідження радикалізму буде актуальна і в подальшому. Успіхи радикалів на виборах, мігрантська і економічна криза, політична нестабільність, масові акції протесту - все це свідчення того, що у крайніх правих і крайніх лівих ще буде шанс вийти на політичну авансцену. Таким чином, демократія зовсім не є панацеєю від розвитку радикальних ідей. Вона, як і інші форми правління, не захищена від сплеску популярності радикалізму. Ключовою причиною, з якої саме в демократичних суспільствах радикали мають найменший ступінь впливу, є широка можливість для вибору. Це дозволяє людині легше знайти політичну силу чи ідеологію, яка в повній мірі відображає іiі інтереси.

Оцінено вплив сучасних технологій і виявлено, що методи поширення радикальних доктрин набувають все нові форми. Це породжує нові загрози для демократії. Уже зараз щорічно зростає кількість протестів і погромів, не кажучи вже про успіхи радикальних політичних сил на виборах, що можна вважати ключовим показником розвитку радикалізму в умовах демократичних суспільств. Головне, що можуть зробити представники політичного істеблішменту демократичних держав, це спробувати знизити напругу шляхом переговорів із представниками радикалів, адже повністю викорінити крайніх правих чи лівих не є можливим.

Таким чином, свобода зібрань та комунікацій і можливість домогтися перемоги легітимним способом роблять сучасні радикальні партії досить популярними. Використовуючи традиційні прийоми (жорстка риторика, наголос на системних і корінних змінах, простота і доступність для кожного), вони фактично пропонують відповіді на питання, які є найбільш обговорюваними в суспільстві. Для демократії радикали представляють певну загрозу, тому від них часто намагаються відгородитися, але не у всіх країнах це проходить однаково успішно. Наприклад, націоналістичні гасла часом приносять додаткові відсотки голосів політичним партіям. Оскільки радикальні доктрини вже $є$ і як і раніше створюються, то немає нічого дивного в тому, що вони є затребуваними і ніякі існуючі види заборон не здатні на 100\% вирішити дану проблематику.

Ключові слова: політичні режими; екстремізм; делегітимація; тероризм; політичні партії; тоталітаризм; продержавний екстремізм

\section{Проблемная ситуация.}

$\mathrm{B}$ заимосвязь между развитием и распространением радикальных идей и формой политического правления является одной из наиболее важных для понимания особенностей востребованности крайне левых и крайне правых доктрин среди населения. Традиционно считается, что в условиях демократии человек может свободно и беспрепятственно высказывать собственную позицию. Благодаря разнообразию политических партий ему проще выбрать ту, которая в наибольшей степени отражает его собственные воззрения. Однако демократические общества порой являются идеальным местом для появления новых радикальных группировок, которые нередко применяют экстремистские методы борьбы для достижения собственных целей. Наиболее характерными примерами подобных организаций были «Красные бригады» в Италии и «Фракция Красной Армии» в ФРГ. В современных обществах поддержка радикализма перешла в несколько иную плоскость. Речь в первую очередь идет о голосовании за них на выборах и участии в демонстрациях.

Несмотря на то, что демократическая форма правления предоставляет большую свободу выбора для населения, далеко не всегда в авангарде политической жизни находятся партии, способные отражать воззрения существенной части населения. Особенно это касается стран, где существует двухпартийная система, а потому определенная часть избирателей не может в полной мере найти отображение собственных взглядов. В обществе, где существует заметная востребованность радикальных действий и лозунгов среди населения, ряд политических деятелей нередко используют тезисы крайне правых или крайне левых в программах своих политических сил или же просто в выступлениях. Это отчетливо прослеживается в программных положениях и высказываниях украинских политических деятелей, которые отказываются от «...мира любой ценой», призывают восстановить ядерный статус и создавать партизанские отряды $[4,5,7]$. В западных странах тезисы обыкновенно носят более умеренный характер и связаны в первую очередь с экономическими 
проблемами. В последние годы также добавляются положения о решении проблем с мигрантами, что также позволят завоевать голоса определенной категории населения.

Цель: выявить факторы, способствующие развитию радикальных идей в условиях демократических обществ.

\section{Анализ исследований и публикаций.}

Если востребованность радикальных идей в условиях тоталитаризма или авторитаризма практически не вызывает сомнений у исследователей данной проблематики, то в отношении демократии ситуация выглядит несколько иначе. Так, ряд исследователей ошибочно считает, что радикализм представляет угрозу только для недемократических форм правления. Например, Т. Ф. Ефремова пишет о том, что радикализм - это политическое течение, ориентирующееся на проведение демократических реформ в рамках существующего государственного строя [2, с. 801]. Автор связывает радикализм с конкретной политической идеологией, более того, его наделяют творческими функциями. Они, безусловно, присутствуют в некоторых радикальных доктринах, но было бы неправильно говорить о том, что все они на первое место ставят именно демократические преобразования. Данное определение более подходит для такого процесca, как «реформаторство», которое также может носить радикальный характер. Радикализм вовсе не априорно нацелен на «демократические реформы», часто сторонники радикальных идей настроены на решительные преобразования, которые идут в разрез с демократическими ценностями.

Проблематика развития и распространения радикальных идей уже больше столетия волнует многих известных ученых, среди которых М. Вебер, Ш. Муфф, М. Яхьяев. Среди современных исследователей проблематики радикализма немало тех, кто скептично относится к демократии и фактически считает, что именно при ней у радикалов есть наиболее высокие шансы добиться успеха. Аргументируется это в первую очередь тем, что даже центристские партии нередко заигрывают с радикализмом не только не препятствуя деятельности радикальных партий и организаций, но и активно используя их риторику и программные положения. Это приводит к увеличению напряженности в обществе, что может вылиться в погромы и массовые акции протеста.

Еще в XX веке исследования Пьера Салмона продемонстрировали, что именно данная форма правления является наиболее благоприятной для развития радикализма. Современные исследователи, например, Донателла дела Порта, лишь подтверждают это и говорят о том, что те свободы, которые существуют у человека при демократии, могут толкнуть его в лоно радикализма [8]. При этом, несмотря на то, что в условиях демократии предполагается, что человек может свободно высказывать свое мнение, появление откровенно на- ционалистических партий всегда вызывает большое сопротивление европейского истеблишмента. Связано это с тем, что представители демократических сил просто не в состоянии смириться с тем, что радикалы добиваются успеха их же методами.

Одной из причин популярности радикалов в условиях демократии является тот факт, что они ставят национальные интересы выше наднациональных. Если левые в этом вопросе могут быть отчасти солидарны с демократами, то ультраправые всегда в первую очередь будут ориентироваться на интересы своего государства (вполне возможно, что даже на интересы конкретной этнической группы, которая является их «ядерным электоратом»). Голосование на выборах за радикалов также свидетельствует о том, что повестка дня, которую предлагают демократические партии, больше не актуальна. В последние годы их популярность только падает. Усугубилось это недавним мигрантским кризисом. Активные протесты населения можно видеть не так часто, зато это выливается в поддержку радикалов. Это вновь хорошо видно на примере Австрии, где на выборах мэра Вены представитель Австрийский партии свободы набрал более $30 \%$ голосов избирателей и лишь немного отстал от победителя гонки. В условиях демократии просто нецелесообразно бороться с ней самой радикальными мерами. В таком случае СМИ выставят протестующих либо в виде клоунов, либо экстремистов, которые несут «угрозу демократии».

В этой связи важно мнение Ш. Муфф, которая считает, что в современном мире бросить вызов концепции демократии и отвергать либеральные воззрения практически нецелесообразно. Именно поэтому количество тех, кто открыто протестует против существующих устоев, достаточно невелико. Исследовательница отмечает, что несмотря на это, вызовы демократии бросаются все чаще [1]. Чтобы представители либеральных партий и сторонники демократии с этим считались, единственным возможным выходом является голосование на выборах за радикалов или экстремистов. Число людей, которые разочаровались в демократии и традиционных партиях, постепенно растет. Вызвано это тем, что их представители больше не способны в полной мере удовлетворить запросы населения. Именно поэтому, как уже было сказано выше, многие политики, даже центристы, включают в свои программы тезисы, используемые радикалами и экстремистами.

Более того, Ш. Муфф отмечает, что даже те люди, которые не поддерживают радикалов, достаточно скептично относятся к действующим политикам. Одним из признаков этого является низкая избирательная активность населения. Уже сейчас в подавляющем большинстве европейских стран на парламентские или президентские выборы не приходит более половины избирателей. Безусловно, причины у них могут быть разные, но 
подобная отстраненность от происходящих политических процессов также заставляет задуматься о том, что для демократии наступили не лучшие времена. Еще чаще голосование за крайне правых или крайне левых рассматривается как знак протеста против существующей системы. Часто оно бывает достаточно спонтанным. В этом случае вспоминается украинский кейс, связанный с партией «Свобода». До парламентских выборов опросы общественного мнения давали ей куда более низкие показатели, чем вышли в итоге. Партия набрала 10, 44\% голосов избирателей, тогда как социологи предрекали не более 6,5\% [3].

\section{Изложение основного материала.}

Радикалы предлагают простые решения сложных проблем, и за счет этого им удается добиться поддержки среди населения. Естественно, положительно влияют на рейтинг радикальных партий и существующие кризисы. Они демонстрируют несостоятельность демократии и неспособность либералов пойти на жесткие меры, которые порой столь необходимы. Проблемы, которые возникают в современных европейских государствах, являются комплексными, но рисковать своим политическим рейтингом не хочет ни одна партия, в результате чего существенные перемены не удается произвести.

Пьер Салмон утверждает, что демократия является благоприятной средой для становления и утверждения радикалистских практик и теорий [11]. Примером этого может служить нынешний подъем популярности радикалов в Европе, в демократических государствах. Это отчетливо видно на примерах Испании, Швеции, Сербии и ряда других стран. Это еще раз подтверждает, что ни одна из форм правления не может быть в полной мере защищена от всплеска популярности и востребованности радикальных идей.

Тот же Салмон рассматривает экстремизм как результат работы обычного демократического политического соревнования или представительной демократии. Определенное количество отдельных вопросов связывается вместе таким образом, чтобы программа была электорально прибыльной и предлагается избирателям. Более того, власть фактически сама может «взростить» радикалов. Поскольку в большинстве европейских стран у руля стоят представители центристских политических партий, они всячески противопоставляют себя радикалам. Делается это для того, чтобы отнять голоса у конкурентов и более респектабельно выглядеть на фоне радикалов. Подобным образом начинает проявляться «прогосударственный экстремизм». В наиболее жестких вариантах он предполагает борьбу с инакомыслием и поиск внешних и внутренних врагов. Данный термин в первую очередь подходит для обществ близких к тоталитарным, однако вполне способен описать ситуацию в ряде трансформирующихся обществ, которые пытаются выстроить новую систему со- циальной реальности, создавая новых героев, мифы, праздники. «Прогосударственный экстремизм» - это способ сплотить населения «законными» методами.

В противном случае, в трансформирующихся обществах нередко становится вопрос о легитимности существующей власти, что является одним из основополагающих факторов, который приводит к экстремистским действиям. Слабость власти, а также ощущение безнаказанности может привести к тому, что вероятность совершения насильственных действий существенно повысится. Дегуманизация и деперсонализация фактически способствуют тому, что экстремистские методы становятся столь популярны. Более того, впоследствии участники подобных акций нередко пытаются легитимировать себя и всячески оправдать свое поведение. Этот тезис подтверждает цитата Надежды Савченко, которая уверяет, что: «теракт в Раде мечтает устроить каждый украинец, но за мечты не судят» [6]

С. Бенхабиб пишет о важности поддержки легитимности для существующей власти, ее залогом она считает наличие свободных и открытых публичных обсуждений тех вопросов, которые вызывают наибольший общественный резонанс [10]. Что касается недостаточной легитимности или ее отсутствия в глазах радикалов, это непременно выльется в экстремистские действия, которые будут направлены против такой власти. Учитывая тот факт, что радикализм ставит перед собой далеко идущие цели, именно момент слабости власти может быть наиболее удачным для воплощения таких планов.

П. Салмон говорит о том, что среди сторонников умеренных партий есть немало людей, которые поддерживают экстремистские позиции по отдельным вопросам, то есть могут составлять потенциальную базу поддержки. Вместе с тем, люди, которые могут разделять взгляды экстремистских групп по отдельным вопросам, могут не чувствовать никакой ответственности за остальные позиции из программы этой же партии, они их совсем не разделяют. То же самое касается ретроспективной оценки экстремистских групп, которая меняется со временем.

Вайнберг и Перлингер в своих исследованиях обнаружили, что политические партии охотнее прибегают к экстремистским методам, когда группа имеет грандиозные цели. Например, установление нового социального порядка, и когда партийная доктрина провозглашает нелегитимность существующего режима. Одновременное восприятие нелегитимности и слабости режима, считают авторы, - необходимое условие возникновения политического экстремизма [12]. С одной стороны, считается, что демократия предоставляет возможность и для участия, и для ненасильственного разрешения конфликтов и обид, для демократий менее вероятно появление насильственных практик. 
С другой стороны, исследования Уильяма Эубанка и Леонарда Вайнберга удивили многих выявлением противоположного. Их вывод: демократические режимы фактически более благоприятные для возникновения таких форм экстремизма, как терроризм, чем авторитарные; политические и гражданские свободы положительно коррелируют с терроризмом благодаря свободе движений и объединений и доступу ко многим потенциальным целям [9]. Свобода, предоставляемая при демократии, фактически развязывает руки радикалам и экстремистам, ведь специальных органов, кроме полиции и служб безопасности государств, для борьбы с ними не существует. В таких условиях легче коммуницировать и разрабатывать план взаимодействия. В тоталитарных государствах существуют специальные органы, призванные бороться с подобными явлениями, именно поэтому шансы на успех у радикалов заметно ниже. Однако в данном случае именно самое государство способно транслировать радикальные позиции.

Ни одна из форм политических систем не существует в чистом виде. Однако если в условиях, которые близки к тоталитарным (например, в нацистской Германии), за людьми устанавливается слежка и их поведение всячески регулируется, то в условиях демократии человек получает гораздо больше свободы. В условиях демократической формы правления человеку представляется больше шансов реализовать свои политические идеи. Однако при мнимой вседозволенности на деле добиться успеха получается у единиц. Несмотря на то, что в демократических государствах нет специальных органов, которые могут вмешаться в деятельность партий, существует система сдержек и противовесов, которая не позволяет представителям крайне правых или крайне левых выйти на политическую авансцену.

Неудивительно, что радикализм, а также экстремистские формы достижения радикальных целей, являются столь популярными в условиях демократии. Это своеобразная защитная реакция, которая вызвана процессами, происходящими в обществе. Демократия все время пытается расширить свои границы и всячески защититься от тоталитаризма и радикализма. Хотя иногда радикалы приходят к власти вполне демократичным путем. Подобные примеры уже были в европейской и мировой истории, особенно XX века. Тот же нацизм постепенно наращивал свою популярность и в итоге утвердился именно при демократии, пусть и достаточно слабой. Для сторонников демократии и демократических режимов особенно страшен тот факт, что радикализм побеждает их же методами. Например, характерный случай произошел в Австрии, где местная Австрийская партия свободы пользуется большой поддержкой среди населения. Для демократов гораздо проще смириться с тем, что радикалы добьются победы или внушительных результатов путем незакон- ных действий или с применением насилия. Когда же радикальные партии добиваются успеха в условиях конкурентной борьбы, это вызывает куда больший шок и резонанс. Неприятие представителями демократических партий радикалов может достигать самых разнообразных форм: от банального нежелания вступать в коалицию до открытой конфронтации.

Уже в начале XXI века была сформирована «теория подковы». Ее автором является французский ученый Ж.-П. Фэй, который утверждает, что крайне левые и крайне правые на самом деле гораздо ближе друг к другу, чем к центристам. Подобное предположение - это настоящая угроза для демократических обществ, особенно тех, в которых существуют явные культурные и исторические расколы. Кейс современной Украины в данном случае ничуть не менее интересен, чем кейс Италии 1970-х годов. Уровень расслоения общества, а также культурные различия между севером и югом, привели к тому, что значительная часть населения готова была поддержать радикалов. Впрочем, примеров, когда ультра правые и ультра левые объединялись между собой, не так много. Связано это с тем, что у них должна возникнуть общая цель, ради которой они могли бы объединиться. Наиболее очевидный вариант - это интервенция другого государства, когда отбрасываются политические разногласия и ведется совместная борьба. Также подобные ситуации имеют место в среде футбольных фанатов, когда проходят матчи национальной сборной. «Теория подковы» хорошо подходит для обществ, которые находятся в революционном или предреволюционном состоянии, когда многие политические акторы ищут себе союзников и готовы ради сиюминутной выгоды взаимодействовать со вчерашними политическими оппонентами.

В условиях демократии представители крайних течений могут добиться успеха за счет популизма и акцентируя внимание на злободневных проблемах. Скептицизм современных избирателей достаточно высок, поэтому вероятность достижения положительного результата достаточно немаленькая. Основным сдерживающим фактором, по мнению М. Головина, является законодательство некоторых стран, а также особенности избирательной системы [1]. Благодаря этому демократические партии почти всегда могут пойти на сближение друг с другом исключительно с целью не появления радикалов на политической авансцене. Однако все чаще представителям данных политических сил удается стать частью местного истеблишмента. Более того, они могут играть ключевую роль в политике государства, как это происходит в той же Франции.

Сейчас формы воплощения радикализма чрезвычайно быстро меняются. Развитие информационных технологий не только привело к тому, что каждый имеет шанс поделиться с окружающим 
миром своей точкой зрения по поводу того или иного события. Социальные сети стали платформой, посредством которой люди начинают искать себе подобных и объединяться в группы по интересам. Таким образом - это отличное место для рекрутеров, которые заинтересованы в новых членах в радикальных организациях или партиях. Уже сейчас с помощью социальных сетей происходят существенные изменения в мире. В дальнейшем их роль будет только увеличиваться и это является крайне интересной темой для изучения.

\section{Выводы.}

Установлено, что проблематика исследования радикализма будет актуальна и в дальнейшем. Среди факторов, которые непосредственно влияют на успехи радикальных политических партий можно выделить: мигрантский и экономический кризис, политическую нестабильность, наличие внешней угрозы, расслоение общества. Развитию и популяризации радикальных идей способствуют: свобода собраний и передвижений, отсутствие контроля со стороны государства, лояльное отношение власти к актам экстремизма и массовым акциям протеста. Таким образом, цель статьи считается выполненной.

Проходящие массовые акции протеста - свидетельства того, что у крайне правых и крайне левых еще будет шанс выйти на политическую авансцену. Демократия вовсе не является панацеей от развития радикальных идей. Она, как и другие формы правления, не защищена от всплеска популярности радикализма. Ключевой причиной, по которой именно в демократических обществах радикалы имеют наименьшую степень влияния, является широкая возможность для выбора. Это позволяет человеку легче найти политическую силу или идеологию, которая в полной мере ото- бражает его интересы.

Оценено влияние современных технологий и выявлено, что методы распространения радикальных доктрин приобретают все новые формы. Это порождает новые угрозы для демократии. Уже сейчас ежегодно возрастает количество протестов и погромов, не говоря уже об успехах радикальных политических сил на выборах, что можно считать ключевым показателем развития радикализма в условиях демократических обществ. Главное, что могут сделать представители политического истеблишмента демократических государств, это попытаться снизить напряжение путем переговоров с представителями радикалов, ведь полностью искоренить крайне правых или крайне левых не представляется возможным.

Таким образом, свобода собраний и коммуникаций и возможность добиться победы легитимным способом делают современные радикальные партии достаточно популярными. Используя традиционные приемы (жесткая риторика, упор на системные и коренные изменения, простота и доступность для каждого), они фактически предлагают ответы на вопросы, которые являются наиболее обсуждаемыми в обществе. Для демократии радикалы представляют определенную угрозу, поэтому от них часто пытаются оградиться, но не во всех странах это проходит одинаково успешно. Например, националистические лозунги порой приносят дополнительные проценты голосов политическим партиям. Поскольку радикальные доктрины уже имеются и по-прежнему создаются, то нет ничего удивительного в том, что они являются востребованными и никакие существующие виды запретов не способны на $100 \%$ разрешить данную проблематику.

\section{БІБІЛІОГРАФІЧНІ ПОСИЛАННЯ}

1) Головин М. Демократия и правый радикализм: политические процессы в Европе / М. Головин // International studies. - 2016. - 1 февраля. - Режим доступа: http://internationalstudies.ru/stati/evropa/item/56-demokratiya-i-pravyjradikalizm-osobennosti-politicheskogo-protsessa-v-sovremennoj-evrope.html

2) Ефремова Т. Ф. Новый словарь русского языка. Толково-словообразовательный / Т. Ф. Ефремова. - М.: Русский язык, 2000. - 1233 с.

3) Пешко К. «Выборы-2012: феноменальная социология» / К. Пешко // Главком. - 2012. - 31 октября. - Режим доступа: https://glavcom.ua/publications/119089-vybory-2012-fenomenalnaja-sotsiologija.html

4) Програма партії Всеукраїнське Об’єднання «Батьківщина». - Режим доступу: http://ba.org.ua/programm/

5) Програма Радикальної партії Олега Ляшка. - Режим доступу: http://liashko.ua/program?attempt=1\#sthash. LlG0kKtr.dpuf

6) «Савченко: Теракт в Раде - об этом мечтает каждый украинец, но за мечты не судят» // 2000.ua. - 2018. - 22 марта. - Режим доступа: https://2000.ua/novosti/ukraina novosti/savchenko-terakt-v-rade---ob-etom-mechtaet-kazhdyiukrainec_no-za-mechty-ne-sudjat.html

7) «Украина может восстановить статус ядерной державы», - Ляшко // Канал 24. - Архив новостей - Режим доступа: http://24tv.ua/ru/ukraina_mozhet_vosstanovit_status_yadernoy_derzhavi_lyashko_n424241

8) Della Porta D. Social Movements, Political Violence, and the State: $\bar{A}$ Comparative Analysis of Italy and Germany / D. Della Porta. - Cambridge; New York: Cambridge University Press, 1996. - 292 P.

9) Eubank W. L. Terrorism and Democracy: Perpetrators and Victims / W. L. Eubank, L. Weinberg // Terrorism and Political Violence. - 2001. - Vol. 13. - № 1. - P. 155-164.

10) Mouffe Ch. For an Agonistic Model of Democracy, in Id / Ch. Mouffe // The Democratic Paradox. - London, Verso, 2000. - P. 80-107 
11) Political extremism and Rationality / Albert Breton, Gianluigi Galeotti, Piere Salmon and Ronald Wintrobe (eds.). Cambridge: Cambridge University press, 2002.

12) Weinberg L. Political Parties and Terrorist Groups / L. Weinberg, A. Pedahzur, A. Perlinger. - New York: Routledge, 2008. $-200 \mathrm{p}$

\section{REFERENCES}

1) Golovin, M. (2016). Demokratiia i pravyi radikalizm: politicheskie protcessy v Evrope [Democracy and Right-wing Radicalism: Political Processes in Europe]. International studies. Retrieved from: http://internationalstudies.ru/stati/ evropa/item/56-demokratiya-i-pravyj-radikalizm-osobennosti-politicheskogo-protsessa-v-sovremennoj-evrope.html [in Russian].

2) Efremova, T.F. (2000). Novyi slovar russkogo iazyka. Tolkovo-slovoobrazovatelnyi [New Dictionary of Russian. Interpretative and word-building]. Moscow: Russkii iazyk [in Russian].

3) Peshko K. (2012). Vybory-2012: fenomenalnaia sotciologiia [Elections 2012: phenomenal sociology]. Glavkom Commander. Retrieved from: https://glavcom.ua/publications/119089-vybory-2012-fenomenalnaja-sotsiologija.html [in Russian].

4) Prohrama partii Vseukrainske Obiednannia «Batkivshchyna» [The program of the All-Ukrainian Association «Fatherland»]. (n.d.). Retrieved from: http://ba.org.ua/programm/ [in Ukrainian].

5) Prohrama Radykalnoi partii Oleha Liashka [Program of the Radical Party Oleg Lyashko]. (n.d.). Retrieved from: http://liashko.ua/program?attempt=1\#sthash.LlG0kKtr.dpuf [in Ukrainian].

6) «Savchenko: Terakt v Rade - ob etom mechtaet kazhdyi ukrainetc, no za mechty ne sudiat» [«Savchenko: Terror in the Parliament - Every Ukrainian dreams about this, but they do not judge dreams»]. (2018). 2000.ua. Retrieved from: https://2000.ua/novosti/ukraina_novosti/savchenko-terakt-v-rade---ob-etom-mechtaet-kazhdyi-ukrainec_-no-za-mechtyne-sudjat.htm [in Russian].

7) «Ukraina mozhet vosstanovit status iadernoi derzhavy», - Liashko (2014) [«Ukraine can restore the status of a nuclear power», - Lyashko]. Kanal 24 - Channel 24. Retrieved from: http://24tv.ua/ru/ukraina_mozhet_vosstanovit_status_ yadernoy derzhavi lyashko_n424241[in Russian].

8) Della Porta, D. (1996). Social Movements, Political Violence, and the State: A Comparative Analysis of Italy and Germany. New York: Cambridge University Press.

9) Eubank, W.L. (2001). Terrorism and Democracy: Perpetrators and Victims. Terrorism and Political Violence, 13 (1), 155-164.

10) Mouffe, Ch. (2009). For an Agonistic Model of Democracy, in Id. The Democratic Paradox (Pp. 80-107). London, Verso.

11) Breton, A., Galeotti, G., Salmon, P., \& Wintrobe, R. (Eds.). (2002). Political extremism and Rationality. Cambridge: Cambridge University press. Retrieved from: http://books.google.com/books?id=yyUmy7SJra4C\&printsec=frontcover\& $\mathrm{hl}=$ ru\&sou $\mathrm{rce}=\mathrm{gbs}$ navlinks $\mathrm{s} \# \mathrm{v}=$ onepage $\& \mathrm{q}=\& \mathrm{f}=$ false

12) Weinberg, L., Pedahzur, A., \& Perlinger, A. (2008). Political Parties and Terrorist Groups. New York: Routledge.

\section{Музылёв Александр Владимирович}

\section{Аспирант}

Харьковский национальный университет имени В. Н. Каразина

61000, г. Харьков, площадь Свободы, 4

\section{Muzylov Oleksandr V.}

Post-graduate student

V. N. Karazin Kharkiv National University

4, Svobody Sq., Kharkiv, 61000, Ukraine

Email: santiagoreddev@gmail.com

Цитування: Музильов А. Розвиток і поширення радикальних ідей в умовах сучасних демократичних суспільств / А. Музильов // Науково-теоретичний альманах «Грані». - 2018. - Т. 21. - № 4. - С. 65-71.

Citation: Muzylov, O. (2018). Rozvytok i poshyrennya radykal'nykh idey v umovakh suchasnykh demokratychnykh suspil'stv [Development and dissemination of radical ideas in the conditions of modern democratic societies]. Scientific and theoretical almanac «Grani», 21(4), 65-71. 